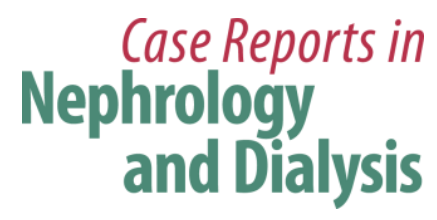

Case Rep Nephrol Dial 2019;9:15-24

DOI: $10.1159 / 000498939$

Published online: March 21, 2019

(C) 2019 The Author(s)

Published by S. Karger AG, Basel

www.karger.com/cnd

This article is licensed under the Creative Commons Attribution-NonCommercial 4.0 International License (CC BY-NC) (http://www.karger.com/Services/OpenAccessLicense). Usage and distribution for commercial purposes requires written permission.

\title{
MPGN Type 3 Associated with Pemphigus Herpetiformis Mimicking PGNMID and Dermatitis Herpetiformis
}

\author{
Yoshio Shimizu $^{\text {a, b }}$ Keiichi Wakabayashi ${ }^{a}$ Yoko Hayashi ${ }^{a}$ Kazuaki Hara \\ Rumi Aoyama $^{a}$ Takahiro Niimi ${ }^{a}$ Yasuhiko Tomino ${ }^{c}$ Ryo Wada ${ }^{d}$ \\ Maki Hata ${ }^{e}$ Yusuke Suzuki ${ }^{f}$ \\ aDivision of Nephrology, Department of Internal Medicine, Juntendo University Shizuoka \\ Hospital, Izunokuni, Japan; ' Shizuoka Medical Research Center for Disaster, Juntendo \\ University, Izunokuni, Japan; 'Asian Pacific Renal Research Promotion Office, Medical \\ Corporation Showakai, Tokyo, Japan; dDivision of Pathology, Juntendo University \\ Shizuoka Hospital, Izunokuni, Japan; eDepartment of Dermatology, Numazu Municipal \\ Hospital, Numazu, Japan; ' Department of Nephrology, Juntendo University Faculty of \\ Medicine, Tokyo, Japan
}

\section{Keywords}

MPGN type 3 - Proliferative glomerulonephritis with monoclonal lgG deposits - Pemphigus herpetiformis · Dermatitis herpetiformis
Abstract

A 45-year-old man suffering from dermal blistering disease with proteinuria and hematuria underwent renal biopsy. The renal biopsy specimen suggested proliferative glomerulonephritis with monoclonal IgG deposits under routine light, immunofluorescence and electron microscopy. The staining for $\lg G$ subclasses (IgG1 and $\lg G 2$ ) and $k / \lambda$ light chain indicated secondary 


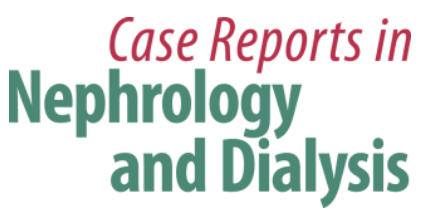

\begin{tabular}{l|l} 
Case Rep Nephrol Dial 2019;9:15-24 \\
\hline DOI: 10.1159/000498939 & $\begin{array}{l}\text { (c) } 2019 \text { The Author(s). Published by S. Karger AG, Basel } \\
\text { www.karger.com/cnd }\end{array}$
\end{tabular}

Shimizu et al.: MPGN Type 3 Associated with Pemphigus Herpetiformis Mimicking PGNMID and Dermatitis Herpetiformis

immune complex type MPGN type 3. The patient had been diagnosed as having dermatitis herpetiformis $(\mathrm{DH})$, a phenotype of gluten hypersensitivity prior to the appearance of the renal abnormality. Although common autoantibodies might be related to the pathogenesis of disorders in the skin and kidney, DH is mainly driven by lgA autoantibody, while MPGN is induced by IgG immune complexes. IgA was not observed in the glomeruli by immunofluorescence. Neither the examination for DH specific autoantibodies nor HLA-DQB1 genotype supported the diagnosis of $\mathrm{DH}$. Reassessment of the skin biopsy record revealed that the blister was localized in the epidermis, suggesting pemphigus herpetiformis by IgG class anti-epidermal autoantibody, which also affected the renal disorder.

(C) 2019 The Author(s)

Published by S. Karger AG, Basel

\section{Introduction}

While immunoglobulins play a main role in humoral immunity, they sometimes induce various disorders involving many organs. Kidney and skin are also targets of immunoglobulinassociated disorders [1]. We present a case of a 45-year-old male with MPGN type 3 with blistering skin disease. He was previously diagnosed as having dermatitis herpetiformis (DH) by skin biopsy. It was speculated that the skin and renal disorders were due to a common autoantibody, but there was a discrepancy in the immunoglobulin class of the pathogenic autoantibodies between DH and MPGN. Reassessment of the histopathological findings in skin biopsy corrected the patient's diagnosis to pemphigus herpetiformis. Thus, this patient showed complex phenotypes in the kidney and skin that made it difficult to provide differential diagnoses.

\section{Case Report}

A 45-year-old Japanese male was found to have microscopic hematuria and proteinuria at the annual medical checkup. He was referred to the Juntendo University Shizuoka Hospital for further examination, by a local medical doctor. He had been working in general good health. Initial examination was normal but skin erythema on the trunk and extremities was treated in the dermatology clinic.

The patient was well-developed and well-nourished. His blood pressure in the sitting position was 138/76 mm Hg and pulse rate 66 beats per minute. His skin tanned well and was free of vesicles. Urinalysis showed a 2+ dipstick test for protein, $1+$ for occult blood and was negative for sugar. Urinary sediments showed 10-19 red blood cells/HPF in the urinary sediments. The urinary protein-to-creatinine ratio was $1.2 \mathrm{~g} / \mathrm{gCr}$. Laboratory tests revealed serum urea nitrogen $12.1 \mathrm{mg} / \mathrm{dL}$ (normal values: $9-21 \mathrm{mg} / \mathrm{dL}$ ), creatinine $0.68 \mathrm{mg} / \mathrm{dL}(0.4-0.9$ $\mathrm{mg} / \mathrm{dL})$, uric acid $7.5 \mathrm{mg} / \mathrm{dL}(3.8-7.5 \mathrm{mg} / \mathrm{dL})$ and an estimated glomerular filtration rate (eGFR) of $99.2 \mathrm{~mL} / \mathrm{min} / 1.73 \mathrm{~m}^{2}$ (based upon the serum creatinine). The hematologic evaluations, liver function, serum cholesterol and serological tests were within normal ranges. Serological markers for syphilis, hepatitis B virus and hepatitis $C$ virus were negative. Serum immunoelectrophoresis showed normal IgG, IgA and IgM precipitin arcs. Tests for anti-nuclear antibodies, anti-DNA antibodies, PR3-ANCA, MPO-ANCA and anti-glomerular basement membrane (anti-GBM) antibodies were negative. The complement 3 (C3) and C4 levels were within 


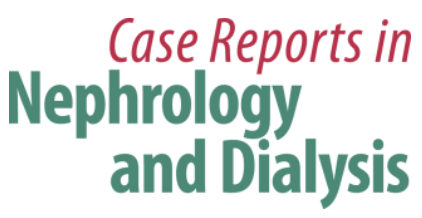

Case Rep Nephrol Dial 2019;9:15-24

normal ranges (Table 1). There were no findings suggestive of malignancy in the chest and abdominal X-ray and CT.

During renal biopsy, three cores were obtained by ultrasound guided needle biopsy. The renal cortex was approximately $70 \%$. The LM showed 30 glomeruli. Three glomeruli were globally sclerosed and focal tubular atrophy with interstitial fibrosis and inflammatory cell infiltration were observed around them (Fig. 1a). The glomeruli showed moderate mesangial widening and thickening of the capillary walls. Lobular accentuation with segmental nodular formation due to an increase in cells and matrix were also observed (Fig. 1b). The majority of glomerular capillary loops showed double contours (Fig. 1c). In immunofluorescence, IgG, C3 and $\mathrm{C} 1 \mathrm{q}$ were strongly positive in the granular deposits along the glomerular capillary walls and mesangial areas (Fig. 1d, g, h). IgA, IgM and fibrinogen revealed weak or negative signals (Fig. 1e, f). In electron microscopy, foot processes of glomerular epithelial cells were effaced (Fig. 2a). Massive electron-dense deposits (EDDs) were observed in the glomerular mesangial areas, basement membranes, subendothelial areas and subepithelial areas (Fig. 2b). Mesangial matrices and the numbers of cells were increased moderately. In the capillary loops, the GBM showed segmental doubling with EDDs located between the GBM. No inflammatory cells were observed in the glomerular capillary loops (Fig. 2c). The EDDs exhibited immune complex-like granular structures (Fig. 2d).

The findings are summarized as the Burkholder variant of MPGN type 3 [2] and considered in the differential diagnosis of proliferative glomerulonephritis with monoclonal IgG deposits (PGNMID). Immunofluorescence for anti-IgG1 and IgG2 antibodies were positive in both the glomerular capillary loops and the mesangial areas (Fig. 3a, b). Staining for anti-IgG3 and IgG4 antibodies was negative (data not shown). Immunohistochemistry revealed that the IgG deposited within the glomeruli were both $\kappa$ and $\lambda$ positive, suggesting that polymeric IgG was deposited in the glomeruli (Fig. 3c, d).

Since adult idiopathic MPGN is rare and the current pathological findings were atypical for primary MPGN, the patient's skin lesion, which had been treated for a long time, was examined in detail [3]. Twenty years ago, the patient had suffered from many blisters accompanied by severe itching. He was diagnosed as having DH by skin biopsy and treated with dapsone (diaphenylsulfone) $75 \mathrm{mg} /$ day for 2 years. Seven years later, the DH recurred, and the patient was again treated with the same dose of dapsone. Since he responded well to the treatment, the dose of the drug was decreased to $50 \mathrm{mg} /$ day and the treatment continued. During our clinical observation, the patient accidentally stopped taking dapsone. He noticed the onset of skin blisters and took a photo. The skin lesions quickly diminished after reinitiation of the dapsone treatment.

Since DH is recognized as a phenotype of gluten hypersensitivity, including celiac disease [4], and has a close relationship with specific HLA-DQB1 genotype covering serotype DQ2 and DQ8 in Europe and the United States [5], HLA-DQB1 typing was performed for the patient. His allele (1) was 06: 02 and allele (2) was 06: 04, corresponding to serotype DQ6(1)/DQ6(1), which is commonly observed among the Japanese community and is distinct from the gluten hypersensitivity-related allele [6]. Neither anti-tissue transglutaminase IgA antibody (antitTG IgA) nor anti-endomysial antibody (anti-EMA), autoantibodies specific to celiac disease, were detected in the patient's serum [7]. While IgG immune complex was predominantly observed in the renal biopsy specimen, there was little evidence indicating that the patient was affected with DH. In his past medical records, skin biopsy specimens were not examined by 


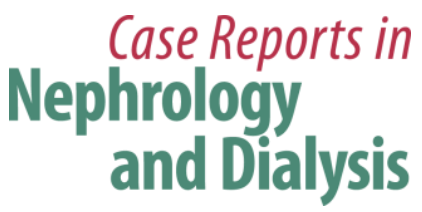

\begin{tabular}{l|l} 
Case Rep Nephrol Dial 2019;9:15-24 \\
\hline DOI: 10.1159/000498939 & $\begin{array}{l}\text { (c) } 2019 \text { The Author(s). Published by S. Karger AG, Basel } \\
\text { www.karger.com/cnd }\end{array}$
\end{tabular}

Shimizu et al.: MPGN Type 3 Associated with Pemphigus Herpetiformis Mimicking PGNMID and Dermatitis Herpetiformis

immunofluorescence but only by light microscopy. The light microscopy specimen revealed that the blister was localized to the epidermis with accompanying edema. These findings did not suggest $\mathrm{DH}$, but rather herpetiformis pemphigoid related to IgG autoantibodies against dermal antigens [8]. Histologically, DH exhibits subepidermal papillary blisters with infiltration of numerous neutrophils and variable eosinophils [4].

The patient was treated with the angiotensin II receptor blocker (ARB), losartan $50 \mathrm{mg}$, daily and dapsone, which is commonly used to treat pemphigus herpetiformis [9]. The treatments decreased the urinary protein excretion to below $0.5 \mathrm{~g} / \mathrm{gCr}$ and did not impair renal function. The blood pressure remained below 130/80 $\mathrm{mm} \mathrm{Hg}$. The skin problems were also well-controlled.

\section{Discussion}

Prior to performing renal biopsy, we anticipated mild glomerulonephritis including IgA nephropathy (IgAN), based upon the clinical findings. In IgAN patients, recurrent episodes of visible hematuria or asymptomatic invisible hematuria, with or without proteinuria, are commonly observed [10]. IgAN, the most common form of glomerulonephritis and the major cause of end-stage kidney disease worldwide, is characterized by the presence of IgA1 deposits, often accompanied by C3 and IgG in glomerular mesangial areas [10].

Light microscopic findings suggested MPGN, and immunofluorescence revealed the dominant presence of IgG, C3 and C1q and subordinate IgA and IgM deposits in the glomeruli, supporting immunoglobulin-positive MPGN [11]. IgAN and C3 glomerulopathy were excluded from the potential candidates. Electron microscopic findings showed MPGN type 3 and the structure of the EDDs were granular, suggesting an immune complex type [12].

The pathologist suggested MPGN type 3 or PGNMID as the differential diagnosis and recommended assessment of the clonality of the deposited immunoglobulins in the glomeruli. PGNMID was reported by Nasr et al. [13] in 2009 as a proliferative glomerulonephritis with monoclonal IgG deposits, which is a form of renal involvement by monoclonal gammopathy, mimicking immune complex type glomerulonephritis. The histologic patterns are predominantly MPGN (57\%), endocapillary proliferative (35\%) with membranous features. Electron microscopy revealed granular, non-organized EDDs, and immunofluorescence microscopy demonstrated both single light-chain and heavy-chain subtypes [13]. While monoclonal IgG deposits in the glomeruli, M-proteins are not always found in the sera (29.7\%) [13]. In our patient, PGNMID was excluded since the immunoglobulins were polyclonal (Fig. 3).

Based upon the current findings, infection, malignancy or drug related immunoglobulin positive MPGN was not suggestive. Since most cases of MPGN are secondary, for which an underlying cause can be found, the patient's skin disease, DH, was highlighted [12]. In the western community, gluten hypersensitivity is a well-known allergic disease [7]. Multiple phenotypes, including DH, celiac disease, mild depression, attention deficit/hyperactivity disorder (ADHD)-like behavior, abdominal pain, diarrhea, constipation, headache, bone and joint pain and chronic fatigue, are recognized as the gluten hypersensitivity family $[7,14]$.

DH is an IgA-mediated cutaneous disease, with IgA deposits appearing in a granular pattern at the top of the dermal papilla in the sublamina densa area of the basement membrane [15]. The patients with celiac disease associated with MPGN have been reported $[16,17]$. It is 


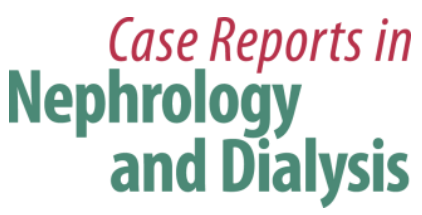

\begin{tabular}{l|l} 
Case Rep Nephrol Dial 2019;9:15-24 \\
\hline DOI: 10.1159/000498939 & $\begin{array}{l}\text { (c) } 2019 \text { The Author(s). Published by S. Karger AG, Basel } \\
\text { www.karger.com/cnd }\end{array}$
\end{tabular}

Shimizu et al.: MPGN Type 3 Associated with Pemphigus Herpetiformis Mimicking PGNMID and Dermatitis Herpetiformis

well known that celiac disease is tightly related to the specific human leukocyte antigen (HLA) class II genes, DQ2 and DQ8 [7]. Approximately 95\% of celiac disease patients express HLADQ2, and the remaining patients have DQ8 among Caucasian patients [18]. Among the Japanese community, these HLA-loci are not common and are also rare among patients with celiac disease [19]. Nutritional disturbance due to malabsorption syndrome is not severe, and these patients exhibit good responses to treatment [20]. The reports of the characteristics of Japanese DH patients show that very few patients have HLA-DQ2 or 8 [21]. Our patient expressed HLA-DQ6(1)/DQ6(1) which is commonly observed among the Japanese population. Gluten is not a trigger for the onset of DH in two-thirds of such patients [21]. Although it is known that anti-tTG IgA and anti-EMA antibody are specific serological markers for the diagnosis of DH and celiac disease, most Japanese patients with DH are negative for these antibodies [21, 22]. It has also been shown that the patients exhibit a good response to dapsone and do not need to avoid dietary gluten [21].

In consideration of the characteristics of the Japanese DH patients, it was difficult to relate the DH and MPGN in our patient, since the predominant renal deposits consisted of IgG class immunoglobulin, while DH is considered IgA-mediated disease. It would have been simpler to understand the etiology of this patient if the renal and dermal manifestations had derived from IgG-class autoantibodies. Re-assessment of the skin biopsy record revealed that the blister was localized in the epidermis, strongly suggesting pemphigus herpetiformis, which is an IgG-related skin disease $[8,9]$.

Our patient showed a favorable clinical course for the skin and renal problems following treatment with dapsone and ARB, i.e. losartan, despite the presence of massive EDDs in the glomeruli. This could support that the MPGN type 3 in this patient was not primary but a secondary derived disease. If we had not performed staining for IgG subclasses or $\kappa / \lambda$ light chains, we would have failed to diagnose the patient correctly and might have harmed the patient by massive immunosuppression, as PGNMID.

\section{Conclusion}

Herein we report the case of a patient with MPGN type 3 associated with pemphigus herpetiformis, which mimics PGNMID and DH. It was suggested that both the renal and dermal manifestations resulted from common IgG class autoantibodies.

\section{Acknowledgments}

We are indebted to the nephrologists, pathologists, and patients at the Juntendo Shizuoka Hospital for their collaboration and participation in this study. We are also grateful to the dermatologists at Numazu Municipal Hospital, Shizuoka, Japan.

\section{Statement of Ethics}

The authors have no ethical conflicts to declare. 


\section{Disclosure Statement}

The authors declare that they have no conflicts of interest to disclose.

\section{Funding Sources}

This study was supported by JSPS KAKENHI grant numbers 26461238 and 17K09039. Shizuoka Medical Research Center for Disaster, Juntendo University is supported by the MEXT-Supported Program from the Strategic Research Foundation at Private Universities, 2015-2019.

\section{References}

1 Vassileva S, Drenovska K, Manuelyan K. Autoimmune blistering dermatoses as systemic diseases. Clin Dermatol. 2014 May-Jun;32(3):364-75.

2 Burkholder PM, Marchand A, Krueger RP. Mixed membranous and proliferative glomerulonephritis. A correlative light, immunofluorescence, and electron microscopic study. Lab Invest. 1970 Nov;23(5):459-79.

3 Fervenza FC, Sethi S, Glassock RJ. Idiopathic membranoproliferative glomerulonephritis: does it exist? [Erratum in: Nephrol Dial Transplant 2013; 28: 1059]. Nephrol Dial Transplant. 2012 Dec;27(12):4288-94.

4 Plotnikova N, Miller JL. Dermatitis herpetiformis. Skin Therapy Lett. 2013 Mar-Apr;18(3):1-3.

5 Megiorni F, Pizzuti A. HLA-DQA1 and HLA-DQB1 in Celiac disease predisposition: practical implications of the HLA molecular typing. J Biomed Sci. 2012 Oct;19(1):88.

6 Ohata C, Ishii N, Niizeki H, Shimomura Y, Furumura M, Inoko H, et al. Unique characteristics in Japanese dermatitis herpetiformis. Br J Dermatol. 2016 Jan;174(1):180-3.

7 Lebwohl B, Ludvigsson JF, Green PH. Celiac disease and non-celiac gluten sensitivity. BMJ. 2015 Oct;351:h4347.

8 Karray M, Badri T: Pemphigus, Herpetiformis. StatPearls [Internet]. Treasure Island: StatPearls Publishing; 2018.

9 Laws PM, Heelan K, Al-Mohammedi F, Walsh S, Shear NH. Pemphigus herpetiformis: a case series and review of the literature. Int J Dermatol. 2015 Sep;54(9):1014-22.

10 Wyatt RJ, Julian BA. IgA nephropathy. N Engl J Med. 2013 Jun;368(25):2402-14.

11 Bomback AS, Appel GB. Pathogenesis of the C3 glomerulopathies and reclassification of MPGN. Nat Rev Nephrol. 2012 Nov;8(11):634-42.

12 Sethi S, Nester CM, Smith RJ. Membranoproliferative glomerulonephritis and C3 glomerulopathy: resolving the confusion. Kidney Int. 2012 Mar;81(5):434-41.

13 Nasr SH, Satoskar A, Markowitz GS, Valeri AM, Appel GB, Stokes MB, et al. Proliferative glomerulonephritis with monoclonal IgG deposits. J Am Soc Nephrol. 2009 Sep;20(9):2055-64.

14 Czaja-Bulsa G. Non coeliac gluten sensitivity - A new disease with gluten intolerance. Clin Nutr. 2015 Apr;34(2):189-94.

15 Mendes FB, Hissa-Elian A, Abreu MA, Gonçalves VS. Review: dermatitis herpetiformis. An Bras Dermatol. 2013 Jul-Aug;88(4):594-9.

16 Jhaveri KD, D’Agati VD, Pursell R, Serur D. Coeliac sprue-associated membranoproliferative glomerulonephritis (MPGN). Nephrol Dial Transplant. 2009 Nov;24(11):3545-8.

17 Biyikli NK, Gökçe I, Cakalağoğlu F, Arbak S, Alpay H. The co-existence of membranoproliferative glomerulonephritis type 1 and coeliac disease: a case report. Pediatr Nephrol. 2009 Jun;24(6):1247-50.

18 Sapone A, Bai JC, Ciacci C, Dolinsek J, Green PH, Hadjivassiliou M, et al. Spectrum of gluten-related disorders: consensus on new nomenclature and classification. BMC Med. 2012 Feb;10(1):13.

19 Watanabe C, Komoto S, Hokari R, Kurihara C, Okada Y, Hozumi H, et al. Prevalence of serum celiac antibody in patients with IBD in Japan. J Gastroenterol. 2014 May;49(5):825-34.

20 Cummins AG, Roberts-Thomson IC. Prevalence of celiac disease in the Asia-Pacific region. J Gastroenterol Hepatol. 2009 Aug;24(8):1347-51. 


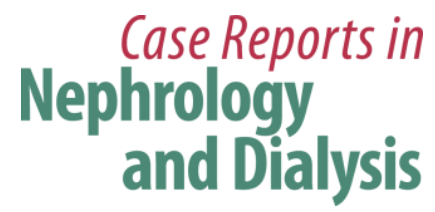
Case Rep Nephrol Dial 2019;9:15-24
DOI: $10.1159 / 000498939$
(C) 2019 The Author(s). Published by S. Karger AG, Basel www.karger.com/cnd

Shimizu et al.: MPGN Type 3 Associated with Pemphigus Herpetiformis Mimicking PGNMID and Dermatitis Herpetiformis

21 Ohata C, Ishii N, Hamada T, Shimomura Y, Niizeki H, Dainichi T, et al. Distinct characteristics in Japanese dermatitis herpetiformis: a review of all 91 Japanese patients over the last 35 years. Clin Dev Immunol. 2012;2012:562168.

22 Asano Y, Makino T, Ishida W, Furuichi M, Shimizu T. Detection of antibodies to epidermal transglutaminase but not tissue transglutaminase in Japanese patients with dermatitis herpetiformis. Br J Dermatol. 2011 Apr;164(4):883-4.
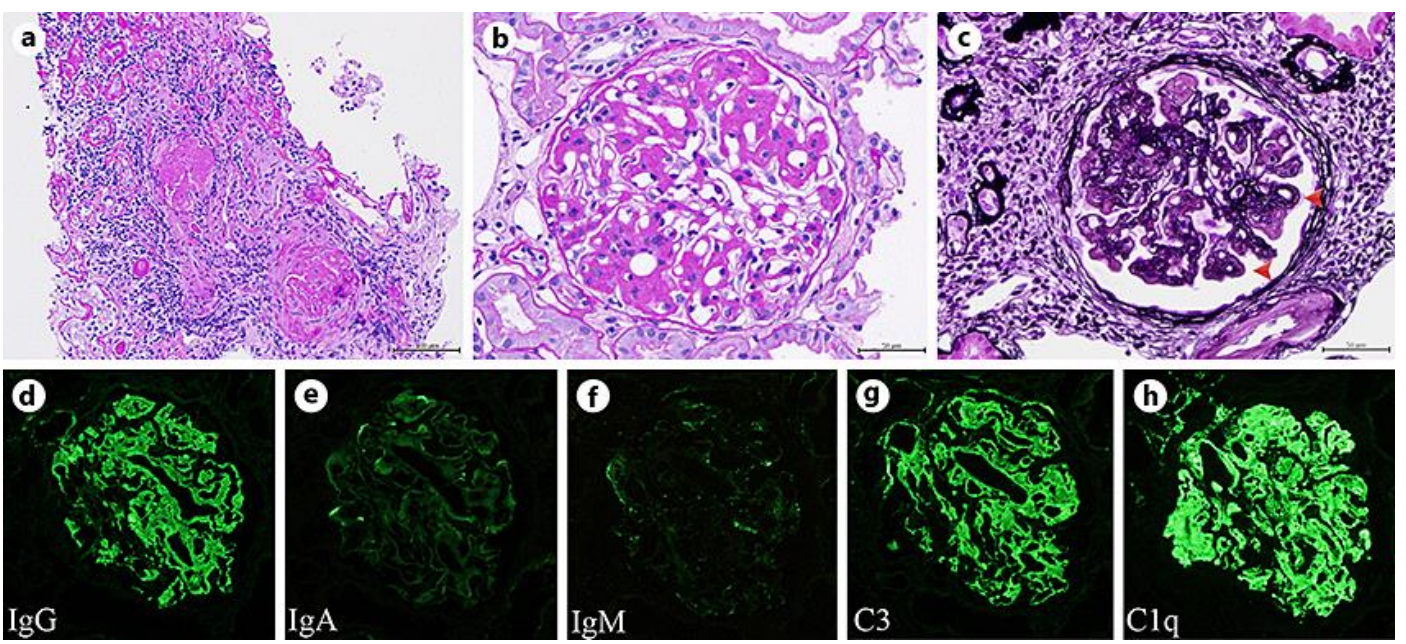

Fig. 1. LM findings of renal biopsy specimens. a Glomerular global sclerosis and focal tubular atrophy with interstitial fibrosis and cellular infiltration (PAS stain, $\times 200$ ). b Lobular accentuation with segmental nodular formation in the glomerulus (PAS stain, $\times 200$ ). c Mesangial enlargement and thickening capillary walls showing double contour (arrowheads) (PASM stain, $\times 400$ ). $\mathbf{d}-\mathbf{h}$ IF findings. Extensive granular deposits of IgG, C3 and Ciq in the glomerular mesangial areas and along the glomerular capillary walls (×200). 


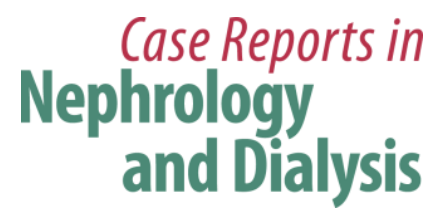

Case Rep Nephrol Dial 2019;9:15-24

DOI: $10.1159 / 000498939$

(C) 2019 The Author(s). Published by S. Karger AG, Basel www.karger.com/cnd

Shimizu et al.: MPGN Type 3 Associated with Pemphigus Herpetiformis Mimicking PGNMID and Dermatitis Herpetiformis
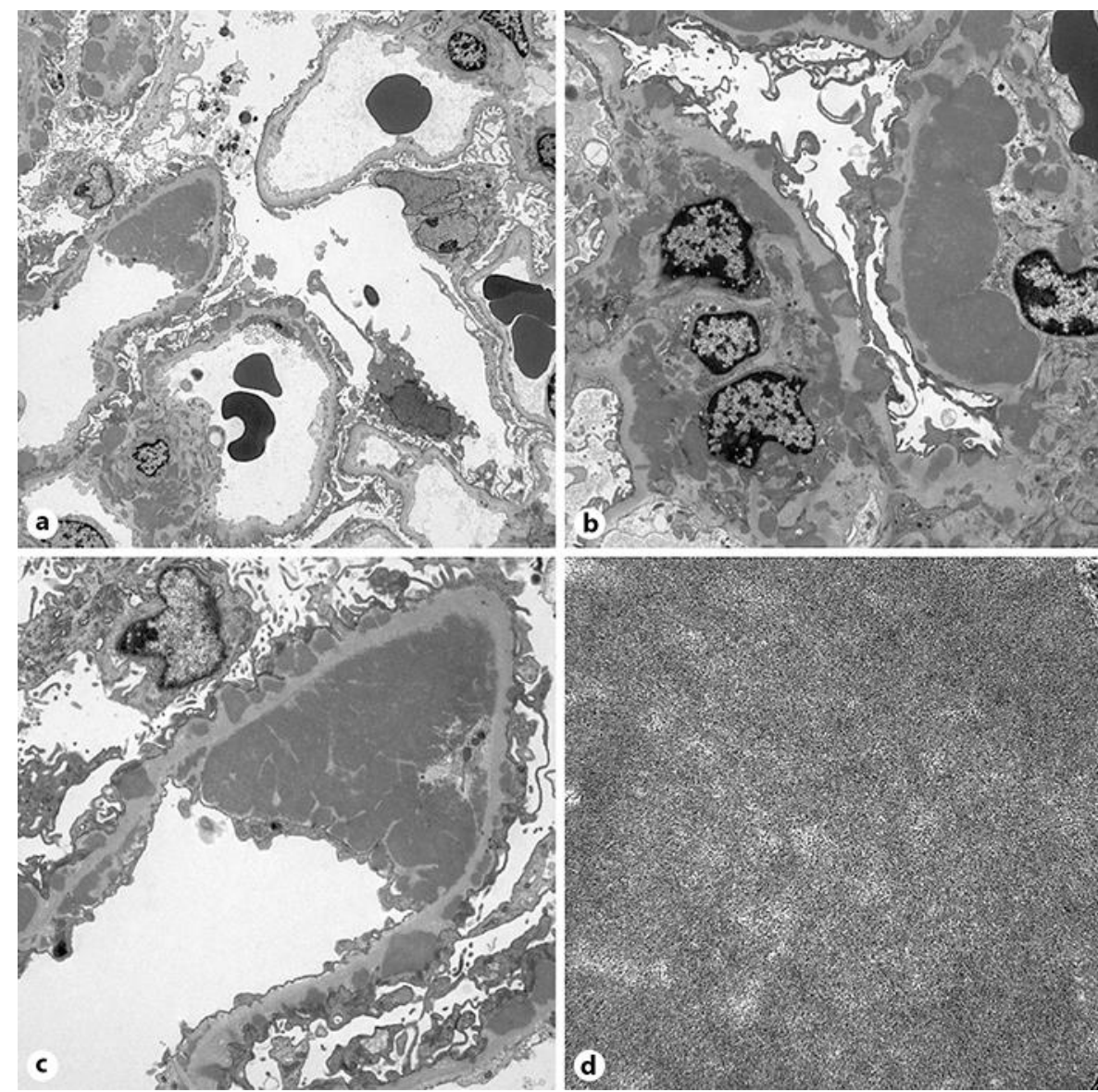

Fig. 2. Electron microscopy findings. a Part of a glomerulus showing epithelial foot process effacement, subendothelial, subepithelial and paramesanial EDDs. EDDs in the glomerular basement membrane (GBM) are observed $(\times 4,600)$. b Massive EDDs in subendothelial, subepithelial and GBM. Hump-like subepithelial deposits are observed $(\times 6,400)$. c A magnified glomerular capillary loop in Figure 3a. A large amount of EDDs in the subendothelial area $(\times 6,400)$. d Unorganized and granular structure of EDDs $(\times 10,000)$. 


\section{Case Reports in Nephrology and Dialysis}

Case Rep Nephrol Dial 2019;9:15-24

DOI: $10.1159 / 000498939$

(C) 2019 The Author(s). Published by S. Karger AG, Basel www.karger.com/cnd

Shimizu et al.: MPGN Type 3 Associated with Pemphigus Herpetiformis Mimicking PGNMID and Dermatitis Herpetiformis
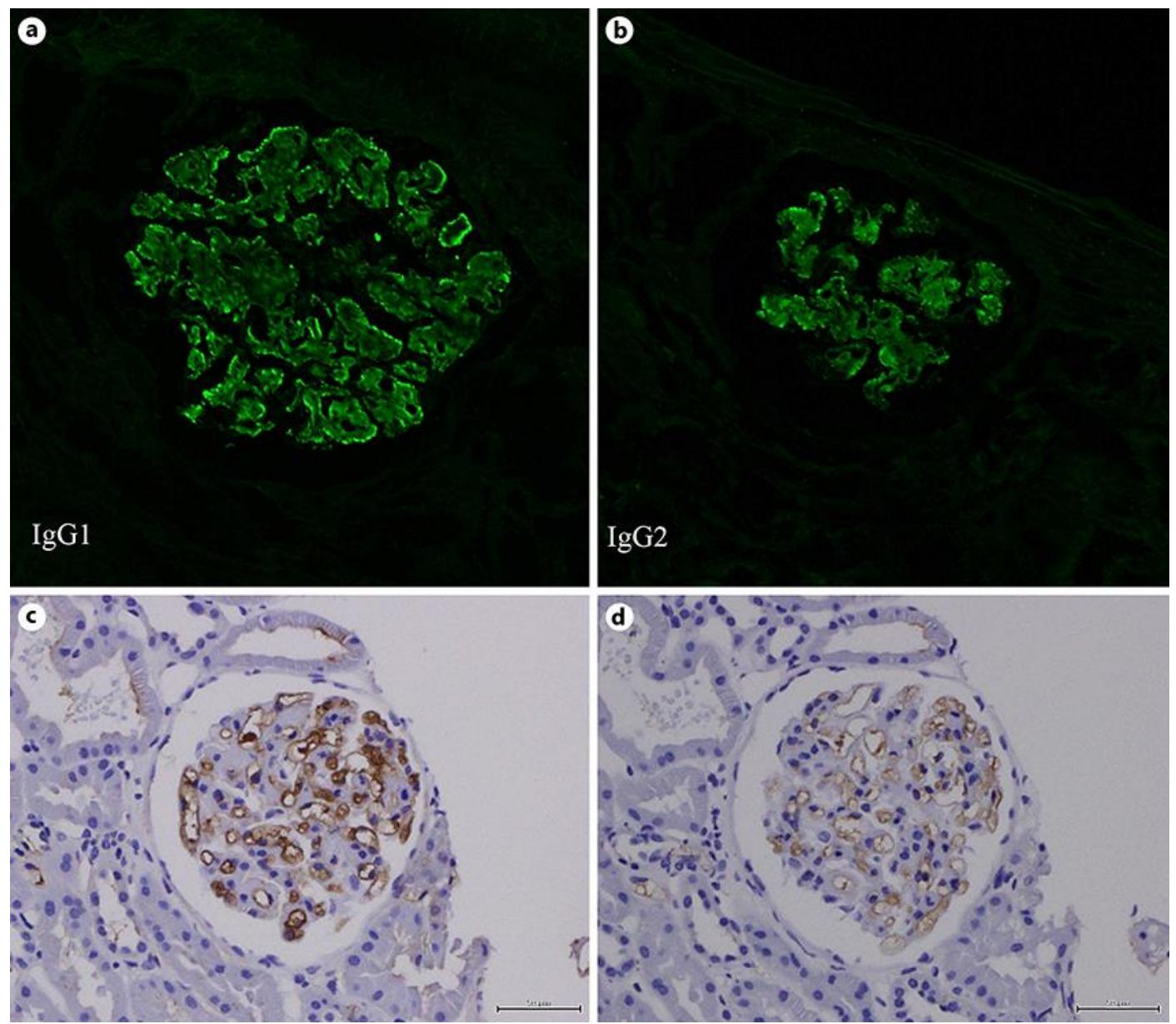

Fig. 3. a, b IF for IgG subclasses. Granular IgG1 and IgG2 deposits are observed in the glomerular mesangial areas and along the glomerular capillary walls $(\times 200)$. c, $\mathbf{d}$ Immunohistochemistry for $\kappa(\mathbf{c})$ and $\lambda(\mathbf{d})$ light chain. Positive staining for both $\kappa$ and $\lambda$ light chains in the glomerular mesangial areas and along the glomerular capillary walls $(\times 200)$. 


\section{Case Reports in Nephrology and Dialysis}

\begin{tabular}{l|l}
\hline Case Rep Nephrol Dial 2019;9:15-24 \\
\hline DOI: 10.1159/000498939 & $\begin{array}{l}\text { @ } 2019 \text { The Author(s). Published by S. Karger AG, Basel } \\
\text { www.karger.com/cnd }\end{array}$ \\
\hline
\end{tabular}
www.karger.com/cnd

Shimizu et al.: MPGN Type 3 Associated with Pemphigus Herpetiformis Mimicking

PGNMID and Dermatitis Herpetiformis

Table 1. Laboratory findings

\begin{tabular}{|c|c|c|c|c|c|c|c|c|c|c|c|}
\hline Urinalysis & & Patient & $\begin{array}{l}\text { Normal } \\
\text { range }\end{array}$ & Chemistry & & Patient & $\begin{array}{l}\text { Normal } \\
\text { range }\end{array}$ & Serology & & Patient & Normal range \\
\hline SG & & 1.018 & $1.015-1.025$ & T.P & $(\mathrm{g} / \mathrm{dL})$ & 6 & $6.3-7.8$ & ANA & & $(-)$ & $(-)$ \\
\hline $\mathrm{pH}$ & & 7 & $5.0-7.8$ & Alb & $(\mathrm{g} / \mathrm{dL})$ & 3.3 & $3.7-4.9$ & ADNA & & $(-)$ & $(-)$ \\
\hline Protein & & $(2+)$ & $(-)$ & AST & (IU/L) & 20 & $11-40$ & IgG & (mg/dL) & 1,624 & $739-1,649$ \\
\hline Occult blood & & $(+)$ & $(-)$ & ALT & (IU/L) & 22 & $6-43$ & $\operatorname{Ig} A$ & (mg/dL) & 693.3 & $107-363$ \\
\hline Glucose & & $(-)$ & $(-)$ & LDH & (IU/L) & 180 & $200-400$ & $\operatorname{Ig} M$ & (mg/dL) & 69.5 & $46-260$ \\
\hline RBC & /HPF & $10-19$ & $<1$ & CPK & (IU/L) & 68 & $57-197$ & Cryoglobulin & & $(-)$ & $(-)$ \\
\hline WBC & /HPF & $1-4$ & $<1-3$ & BUN & $(\mathrm{mg} / \mathrm{dL})$ & 12.1 & $9-21$ & MPO-ANCA & $(\mathrm{EU})$ & $<10$ & $<10$ \\
\hline Dysmorphic RBC & & $(-)$ & & $\mathrm{Cr}$ & $(\mathrm{mg} / \mathrm{dL})$ & 0.68 & $0.4-0.9$ & PR3-ANCA & $(\mathrm{EU})$ & $<10$ & $<10$ \\
\hline Hyaline casts & $/ \mathrm{WF}$ & $(-)$ & $<1-2$ & UA & $(\mathrm{mg} / \mathrm{dL})$ & 7.5 & $3.5-6.9$ & ant-GBM Ab & $(\mathrm{U} / \mathrm{mL})$ & $<7$ & $<7$ \\
\hline Granular casts & & $(-)$ & $(-)$ & $\mathrm{Na}$ & $(\mathrm{mEq} / \mathrm{L})$ & 143 & $135-145$ & $\mathrm{C} 3$ & $(\mathrm{mg} / \mathrm{dL})$ & 80 & $70-130$ \\
\hline \multirow[t]{2}{*}{ Protein } & g/day & 1.2 & $<0.05$ & $\mathrm{~K}$ & $(\mathrm{mEq} / \mathrm{L})$ & 4.2 & $3.5-4.9$ & $\mathrm{C} 4$ & $(\mathrm{mg} / \mathrm{dL})$ & 21.1 & $14-36$ \\
\hline & & & & $\mathrm{Cl}$ & $(\mathrm{mEq} / \mathrm{L})$ & 106 & $96-108$ & ТРНА & & $(-)$ & $(-)$ \\
\hline WBC & $(/ \mu \mathrm{L})$ & 6,100 & $4,700-8,700$ & $\mathrm{P}$ & $(\mathrm{mg} / \mathrm{dL})$ & 3.3 & $2.5-4.5$ & $\mathrm{HCV} \mathrm{Ab}$ & & $(-)$ & $(-)$ \\
\hline $\mathrm{RBC}$ & $\left(\times 10^{4} / \mu \mathrm{L}\right)$ & 470 & $427-500$ & CRP & $(\mathrm{mg} / \mathrm{dL})$ & 0.3 & $<0.5$ & ASO & (IU/mL) & 23 & $<240$ \\
\hline $\mathrm{Hb}$ & $(\mathrm{g} / \mathrm{dL})$ & 14.6 & $13.5-17.6$ & eGFR & $\left(\mathrm{mL} / \mathrm{min} / 1.73 \mathrm{~m}^{2}\right)$ & 99.2 & & & & & \\
\hline $\mathrm{Ht}$ & $(\%)$ & 41.1 & $39.8-51.8$ & & & & & & & & \\
\hline PLT & $\left(\times 10^{4} / \mu \mathrm{L}\right)$ & 22.1 & $15-35$ & & & & & & & & \\
\hline
\end{tabular}

